\title{
In vivo validation of mathematically derived fractional flow reserve for assessing haemodynamics of coronary tandem lesions
}

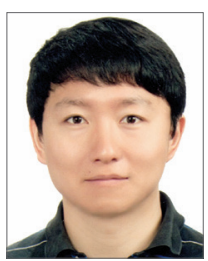

Jihoon Kweon ${ }^{1}, \mathrm{PhD}$; Young-Hak Kim ${ }^{1 *}$, MD; Dong Hyun Yang ${ }^{2}$, MD; June-Goo Lee ${ }^{2}, \mathrm{PhD}$;

Jae-Hyung Roh ${ }^{1}$, MD; Gary S. Mintz ${ }^{3}$, MD; Seung-Whan Lee ${ }^{1}$, MD; Seong-Wook Park ${ }^{1}$, MD

1. Department of Cardiology, University of Ulsan College of Medicine, Asan Medical Center, Seoul, South Korea; 2. Department of Radiology, University of Ulsan College of Medicine, Asan Medical Center, Seoul, South Korea; 3. Cardiovascular Research Foundation, New York, NY, USA

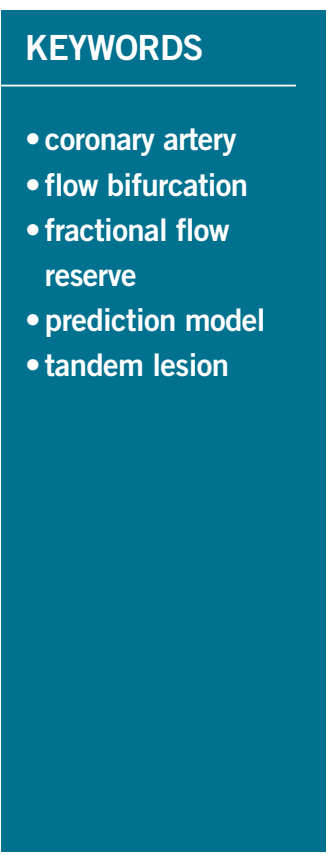

\begin{abstract}
Aims: Our aim was to propose a prediction model for the post-stenting fractional flow reserve (FFR ${ }_{\text {d,pred }}$ ) at a position distal to the tandem lesion.

Methods and results: Using the FFR at a position proximal to the tandem lesion $\left(\mathrm{FFR}_{\mathrm{p}}\right.$ ), and the FFR gradients across proximal $\left(\Delta \mathrm{FFR}_{\mathrm{p}}\right)$ and distal $\left(\Delta \mathrm{FFR}_{\mathrm{d}}\right)$ stenoses, $\mathrm{FFR}_{\mathrm{d} \text {,pred }}^{\prime}$ after treating either the distal or proximal lesion was predicted as $\mathrm{FFR}_{\mathrm{p}}-\Delta \mathrm{FFR}_{\mathrm{p}} /\left(1-1.33 \mathrm{k} \Delta \mathrm{FFR}_{\mathrm{d}}\right)$ or $\mathrm{FFR}_{\mathrm{p}}-\Delta \mathrm{FFR}_{\mathrm{d}} /\left(1-1.33 \Delta \mathrm{FFR}_{\mathrm{p}}\right)$, respectively. The flow fraction of the distal main branch $(\mathrm{k})$ was estimated using the diameter ratio of side to distal main branches. For in vivo validation, 50 patients with a tandem lesion (diameter stenosis $>50 \%$ ) were evaluated. Compared to the conventional model that did not consider side branch flow, our predicted FFR showed closer correlation with the measured FFR $\left(\mathrm{R}^{2}=0.83\right.$ vs. 0.57$)$ and significant reduction in mean absolute errors $(0.034 \pm 0.028$ vs. $0.053 \pm 0.049, \mathrm{p}<0.001)$. In particular, with a large side branch and low baseline FFR, decision making using the current model had greater predictive ability than with the conventional model.
\end{abstract}

Conclusions: By predicting which stenosis is more severe and/or whether the remaining lesion after the first treatment is functionally significant, a tandem prediction model can help to plan optimised stent implantation.

\footnotetext{
*Corresponding author: Asan Medical Center, 88, Olympic-ro 43-Gil, Songpa-gu, Seoul, 138-736, South Korea.
} 


\section{Abbreviations}

FFR

fractional flow reserve

PCI

percutaneous coronary intervention

QCA

\section{Introduction}

Although lesion-specific fractional flow reserve (FFR) is a reliable index for assessing the haemodynamic significance of coronary artery stenosis ${ }^{1}$, a simple FFR measurement cannot predict the true functional severity of each individual stenosis in a tandem lesion (defined as serial stenoses within one coronary artery) due to mutual flow interaction between the stenoses $^{2}$. In terms of optimal treatment sequence, previous studies have recommended that treatment of the stenosis with greater pressure or FFR gradient during pressure wire pullback should be prioritised. Therefore, because the functional severity of the remaining lesion can only be accurately assessed after treatment, a repeated FFR measurement is essential for further decision making ${ }^{3,4}$.

\section{Editorial, see page 1322}

Previous studies using flow phantoms, animal models, and human patients ${ }^{5-7}$ have proposed theoretical equations for predicting the post-stenting FFR. However, these approaches were based on the assumption that there is no side branch between stenoses and that therefore there is a uniform flow rate across stenoses. Considering that the presence of a side branch significantly affects flow recovery after revascularisation and influences the distal

pressure increase ${ }^{6,8}$, an approach that more accurately reflects coronary haemodynamic conditions is necessary. By predicting how many stents are needed and/or which stenosis is more severe, such an approach can help in the planning of optimised stent implantation and facilitate the stent procedure.

The aims of our present study were: 1) to develop and validate a mathematical model of tandem lesions to predict post-stenting FFR across the remaining stenosis, and 2) to propose a relevant approach for optimal treatment.

\section{Methods DEFINITION}

FFR is defined as the ratio of mean coronary pressure to mean aortic pressure at maximal hyperaemia. The FFR gradient across an individual stenosis is represented as $\triangle \mathrm{FFR}\left(\triangle \mathrm{FFR} \mathrm{p}_{\mathrm{p}}=\mathrm{FFR}_{\mathrm{p}}-\mathrm{FFR}_{\mathrm{m}}\right.$ and $\Delta F F R_{d}=F F R_{m}-F F R_{d}$ ) (Figure 1 ). The primary target lesion was defined as the lesion with a larger $\triangle F F R$ between the proximal and distal stenoses. FFR (pre-procedure) and FFR' (post-treatment of the primary target lesion) were obtained from initial and repeated pullback measurements, respectively.

\section{DEVELOPMENT OF THE TANDEM PREDICTION MODEL}

Figure 1A shows serial stenoses with an interposed side branch. Because the pressure gradient across normal lesions is negligible ${ }^{9}$, the distal pressures of the main and side branches are $\mathrm{P}_{\mathrm{d}}$ and $P_{m}$, respectively. At maximum vasodilation, the flow rate to each branch is proportional to the difference between the distal pressure

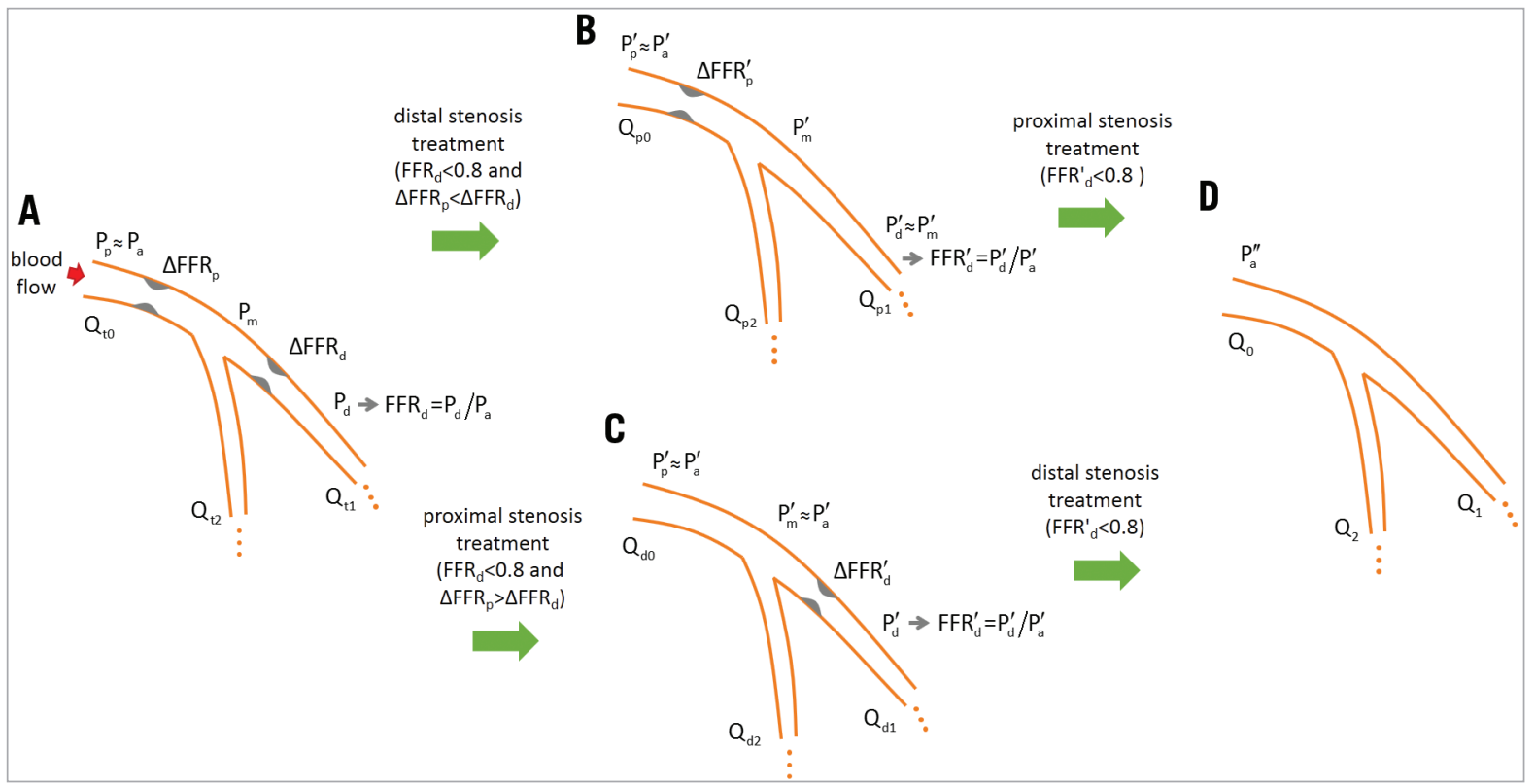

Figure 1. Changes in haemodynamic parameters after stenting. A) Before treatment. B) After distal treatment. C) After proximal treatment. D) After both treatments. Coronary flow rate (Q) is denoted by subscripts according to location (0, ostium; 1, main branch; 2, side branch) and lesion (d: distal; $p$ : proximal; $t$ : tandem). ': after stenting a stenosis; ": after stenting both stenoses; FFR: fractional flow reserve; FFR $F F R_{m}$, and FFR $R_{d}$ FFR values defined at the locations corresponding to $P_{p}, P_{m}$, and $P_{d}$, respectively; $P_{a}:$ mean aortic pressure; $P_{p}, P_{m}$, and $P_{d}$ : mean coronary pressures at positions proximal to the tandem lesion, between stenoses, and distal to the tandem lesion, respectively 
and the wedge pressure $\left(\mathrm{P}_{\mathrm{w}}\right)$. By introducing resistances $\mathrm{R}_{1}$ and $\mathrm{R}_{2}$, the flow rates to the main and side branches are defined as

$$
\mathrm{Q}_{\mathrm{t} 1}=\left(\mathrm{P}_{\mathrm{d}}-\mathrm{P}_{\mathrm{w}}\right) / \mathrm{R}_{1} \text { and } \mathrm{Q}_{\mathrm{t} 2}=\left(\mathrm{P}_{\mathrm{m}}-\mathrm{P}_{\mathrm{w}}\right) / \mathrm{R}_{2} \text {, }
$$

respectively. $\mathrm{P}_{w}$ is assumed to be the same for the main and side branches. After stenting the distal stenosis (Figure 1B), the distal pressure is changed to $\mathrm{P}_{\mathrm{m}}^{\prime}$. The flow rates to the main and side branches become

$$
\mathrm{Q}_{\mathrm{p} 1}=\left(\mathrm{P}_{\mathrm{m}}^{\prime}-\mathrm{P}_{\mathrm{w}}^{\prime}\right) / \mathrm{R}_{1} \text { and } \mathrm{Q}_{\mathrm{p} 2}=\left(\mathrm{P}_{\mathrm{m}}^{\prime}-\mathrm{P}_{\mathrm{w}}^{\prime}\right) / \mathrm{R}_{2} \text {, }
$$

respectively, where $\mathrm{P}_{\mathrm{w}}^{\prime}$ is the wedge pressure post stenting. Likewise, after treating the proximal stenosis (Figure 1C), the distal pressure is changed to $\mathrm{P}_{\mathrm{d}}^{\prime}$. Correspondingly, the flow rate to the main branch becomes

$$
\mathrm{Q}_{\mathrm{dl}}=\left(\mathrm{P}_{\mathrm{d}}^{\prime}-\mathrm{P}_{\mathrm{w}}^{\prime}\right) / \mathrm{R}_{1} \text {. }
$$

To predict the FFR gradient across the proximal stenosis after stenting the distal stenosis, the linear relationship between the flow rate and the trans-stenotic pressure gradient is assumed as

$$
\frac{\mathrm{P}_{\mathrm{a}}-\mathrm{P}_{\mathrm{m}}}{\mathrm{P}_{\mathrm{a}}^{\prime}-\mathrm{P}_{\mathrm{m}}^{\prime}}=\frac{\mathrm{Q}_{\mathrm{t} 1}+\mathrm{Q}_{\mathrm{t} 2}}{\mathrm{Q}_{\mathrm{p} 1}+\mathrm{Q}_{\mathrm{p} 2}}=\frac{\left(\mathrm{P}_{\mathrm{d}}-\mathrm{P}_{\mathrm{w}}\right) / \mathrm{R}_{1}+\left(\mathrm{P}_{\mathrm{m}}-\mathrm{P}_{\mathrm{w}}\right) / \mathrm{R}_{2}}{\left(\mathrm{P}_{\mathrm{m}}^{\prime}-\mathrm{P}_{\mathrm{w}}^{\prime}\right) / \mathrm{R}_{1}+\left(\mathrm{P}_{\mathrm{m}}^{\prime}-\mathrm{P}_{\mathrm{w}}^{\prime}\right) / \mathrm{R}_{2}} .
$$

By dividing with $\mathrm{P}_{\mathrm{a}} / \mathrm{P}^{\prime}$ and using the substitutions

$$
\mathrm{P}_{\mathrm{d}} / \mathrm{P}_{\mathrm{a}}=1-\Delta \mathrm{FFR}_{\mathrm{p}}-\Delta \mathrm{FFR}_{\mathrm{d}}, \mathrm{P}_{\mathrm{m}} / \mathrm{P}_{\mathrm{a}}=1-\Delta \mathrm{FFR}_{\mathrm{p}} \text { and } \mathrm{P}_{\mathrm{m}}^{\prime} / \mathrm{P}_{\mathrm{a}}^{\prime}=1-\Delta \mathrm{FFR}_{\mathrm{p}}^{\prime} \text {, }
$$

(E1) $\frac{\Delta \mathrm{FFR}_{\mathrm{p}}}{\Delta \mathrm{FFR}_{\mathrm{p}}^{\prime}}=\frac{\left(1-\Delta \mathrm{FFR}_{\mathrm{p}}-\Delta \mathrm{FFR}_{\mathrm{d}}\right) / \mathrm{R}_{1}+\left(1-\Delta \mathrm{FFR}_{\mathrm{p}}\right) / \mathrm{R}_{2}-\mathrm{P}_{\mathrm{w}} / \mathrm{P}_{\mathrm{a}} \mathrm{R}_{1}-\mathrm{P}_{\mathrm{w}} / \mathrm{P}_{\mathrm{a}} \mathrm{R}_{2}}{\left(1-\Delta \mathrm{FFR} \mathrm{R}_{\mathrm{p}}^{\prime}\right) / \mathrm{R}_{1}+\left(1-\Delta \mathrm{FFR}_{\mathrm{p}}^{\prime}\right) / \mathrm{R}_{2}-\mathrm{P}_{\mathrm{w}}^{\prime} / \mathrm{P}_{\mathrm{a}}^{\prime} \mathrm{R}_{1}-\mathrm{P}_{\mathrm{w}}^{\prime} / \mathrm{P}_{\mathrm{a}}^{\prime} \mathrm{R}_{2}}$.

For simplicity, we define two coefficients as

(E2) $\mathrm{C}_{1}=\left(1 / \mathrm{R}_{1}+1 / \mathrm{R}_{2}\right)\left(1-\mathrm{P}_{\mathrm{w}} / \mathrm{P}_{\mathrm{a}}\right)=\left(1 / \mathrm{R}_{1}+1 / \mathrm{R}_{2}\right)\left(1-\mathrm{P}_{\mathrm{w}}^{\prime} / \mathrm{P}_{\mathrm{a}}^{\prime}\right)$ and $\mathrm{C}_{2}=1 / \mathrm{R}_{1}+1 / \mathrm{R}_{2}$.

For $\mathrm{C}_{1}$, the relationship between the aortic and wedge pressures is approximated as $\left(\mathrm{P}_{\mathrm{w}}-\mathrm{P}_{\mathrm{v}}\right) /\left(\mathrm{P}_{\mathrm{a}}-\mathrm{P}_{\mathrm{v}}\right) \approx \mathrm{P}_{\mathrm{w}} / \mathrm{P}_{\mathrm{a}}=$ constant, where $\mathrm{P}_{\mathrm{v}}$ is the central venous pressure ${ }^{9}$. Using $\mathrm{C}_{1}$ and $\mathrm{C}_{2}$, equation (E1) is expressed as

$$
\frac{\Delta \mathrm{FFR}_{\mathrm{p}}}{\Delta \mathrm{FFR}_{\mathrm{p}}^{\prime}}=\frac{\mathrm{C}_{1}-\mathrm{C}_{2} \Delta \mathrm{FFR}_{\mathrm{p}}-\Delta \mathrm{FFR}_{\mathrm{d}} / \mathrm{R}_{1}}{\mathrm{C}_{1}-\mathrm{C}_{2} \Delta \mathrm{FFR}_{\mathrm{p}}^{\prime}} .
$$

By multiplying $\left(\mathrm{C}_{1}-\mathrm{C}_{2} \Delta \mathrm{FFR}_{\mathrm{p}}^{\prime}\right) / \Delta \mathrm{FFR}$,

$$
\frac{\mathrm{C}_{1}}{\Delta \mathrm{FFR}_{\mathrm{p}}^{\prime}}-\mathrm{C}_{2}=\frac{\mathrm{C}_{1}-\Delta \mathrm{FFR}_{\mathrm{d}} / \mathrm{R}_{1}}{\Delta \mathrm{FFR}_{\mathrm{p}}}-\mathrm{C}_{2}
$$

By cancelling $\mathrm{C}_{2}$ and taking the inverse,

$$
\Delta \mathrm{FFR}_{\mathrm{p}}^{\prime}=\frac{\Delta \mathrm{FFR}_{\mathrm{p}}}{1-\Delta \mathrm{FFR}_{\mathrm{d}} / \mathrm{R}_{1} \mathrm{C}_{1}} .
$$

For the prediction of $\Delta \mathrm{FFR}_{\mathrm{d}}^{\prime}$, the linear relationship between the flow rate and the pressure gradient across the distal stenosis yields

$$
\frac{\mathrm{P}_{\mathrm{m}}-\mathrm{P}_{\mathrm{d}}}{\mathrm{P}_{\mathrm{a}}^{\prime}-\mathrm{P}_{\mathrm{d}}^{\prime}}=\frac{\mathrm{Q}_{\mathrm{t} 1}}{\mathrm{Q}_{\mathrm{d} 1}}=\frac{\left(\mathrm{P}_{\mathrm{d}}-\mathrm{P}_{\mathrm{w}}\right) / \mathrm{R}_{1}}{\left(\mathrm{P}_{\mathrm{d}}^{\prime}-\mathrm{P}_{\mathrm{w}}^{\prime}\right) / \mathrm{R}_{1}}
$$

By dividing with $\mathrm{P}_{\mathrm{a}} / \mathrm{P}^{\prime}$ and using the substitutions

$$
\mathrm{P}_{\mathrm{d}} / \mathrm{P}_{\mathrm{a}}=1-\Delta \mathrm{FFR}_{\mathrm{p}}-\Delta \mathrm{FFR}_{\mathrm{d}} \text { and } \mathrm{P}_{\mathrm{d}}^{\prime} / \mathrm{P}_{\mathrm{a}}^{\prime}=1-\Delta \mathrm{FFR}_{\mathrm{d}}^{\prime} \text {, }
$$

$$
\frac{\Delta \mathrm{FFR}_{\mathrm{d}}}{\Delta \mathrm{FFR}_{\mathrm{d}}^{\prime}}=\frac{1-\Delta \mathrm{FFR}_{\mathrm{p}}-\Delta \mathrm{FFR}_{\mathrm{d}}-\mathrm{P}_{\mathrm{w}} / \mathrm{P}_{\mathrm{a}}}{1-\Delta \mathrm{FFR}_{\mathrm{d}}^{\prime}-\mathrm{P}_{\mathrm{w}}^{\prime} / \mathrm{P}_{\mathrm{a}}^{\prime}} .
$$

For simplicity, we define a coefficient as

$$
\mathrm{C}_{3}=1-\mathrm{P}_{\mathrm{w}} / \mathrm{P}_{\mathrm{a}}=1-\mathrm{P}_{\mathrm{w}}^{\prime} / \mathrm{P}_{\mathrm{a}}^{\prime} \text {, }
$$

and equation (E4) becomes

$$
\frac{\Delta \mathrm{FFR}_{\mathrm{d}}}{\Delta \mathrm{FFR}_{\mathrm{d}}^{\prime}}=\frac{\mathrm{C}_{3}-\Delta \mathrm{FFR}_{\mathrm{p}}-\Delta \mathrm{FFR}_{\mathrm{d}}}{\mathrm{C}_{3}-\Delta \mathrm{FFR}_{\mathrm{d}}^{\prime}}
$$

Rearrangement gives

$$
\frac{\mathrm{C}_{3}}{\Delta \mathrm{FFR}_{\mathrm{d}}^{\prime}}-1=\frac{\mathrm{C}_{3}-\Delta \mathrm{FFR}_{\mathrm{p}}}{\Delta \mathrm{FFR}_{\mathrm{d}}}-1
$$

and therefore

$$
\Delta \mathrm{FFR}_{\mathrm{d}}^{\prime}=\frac{\Delta \mathrm{FFR}_{\mathrm{d}}}{1-\Delta \mathrm{FFR}_{\mathrm{p}} / \mathrm{C}_{3}}
$$

To estimate $\mathrm{C}_{1}$ and $\mathrm{C}_{2}$, the coronary bifurcation after stenting both stenoses is considered (Figure 1D). In ideal conditions, the distal pressure recovers to the mean aortic pressure $\left(\mathrm{P}_{\mathrm{a}}{ }^{\prime}\right)$. Therefore, the flow rates to the main and side branches are

$$
\mathrm{Q}_{1}=\left(\mathrm{P}_{\mathrm{a}}^{\prime \prime}-\mathrm{P}_{\mathrm{w}}^{\prime \prime}\right) / \mathrm{R}_{1} \text { and } \mathrm{Q}_{1}=\left(\mathrm{P}_{\mathrm{a}}^{\prime \prime}-\mathrm{P}_{\mathrm{w}}^{\prime \prime}\right) / \mathrm{R}_{2} \text {, }
$$

respectively. $\mathrm{P}_{\mathrm{w}}^{\prime \prime}$ is the corresponding wedge pressure. Using the equation (E6), the term $1 / R_{1}+1 / R_{2}$ in $C_{1}$ can be expressed as

$$
\frac{1}{\mathrm{R}_{1}}+\frac{1}{\mathrm{R}_{2}}=\frac{\mathrm{Q}_{1}+\mathrm{Q}_{2}}{\mathrm{P}_{\mathrm{a}}^{\prime \prime}-\mathrm{P}_{\mathrm{w}}^{\prime \prime}} .
$$

By substituting $1 / R_{1}+1 / R_{2}$ into equation (E2),

$$
\mathrm{C}_{1}=\frac{\mathrm{Q}_{1}+\mathrm{Q}_{2}}{\mathrm{P}_{\mathrm{a}}^{\prime \prime}-\mathrm{P}_{\mathrm{w}}^{\prime \prime}}\left(1-\mathrm{P}_{\mathrm{w}} / \mathrm{P}_{\mathrm{a}}\right)=\frac{\mathrm{Q}_{1}+\mathrm{Q}_{2}}{\mathrm{P}_{\mathrm{a}}^{\prime \prime}-\mathrm{P}_{\mathrm{w}}^{\prime \prime}}\left(1-\mathrm{P}_{\mathrm{w}}^{\prime \prime} / \mathrm{P}_{\mathrm{a}}^{\prime \prime}\right)=\frac{\mathrm{Q}_{0}}{\mathrm{P}_{\mathrm{a}}^{\prime \prime}} .
$$

By multiplying $\mathrm{R}_{1}$ and taking the inverse,

$$
\frac{1}{\mathrm{R}_{1} \mathrm{C}_{1}}=\frac{\mathrm{Q}_{1}}{\mathrm{P}_{\mathrm{a}}^{\prime \prime}-\mathrm{P}_{\mathrm{w}}^{\prime \prime}} \frac{\mathrm{P}_{\mathrm{a}}^{\prime \prime}}{\mathrm{Q}_{0}}=\frac{\mathrm{Q}_{1}}{\mathrm{Q}_{0}} \frac{\mathrm{P}_{\mathrm{a}}^{\prime \prime}}{\mathrm{P}_{\mathrm{a}}^{\prime \prime}-\mathrm{P}_{\mathrm{w}}^{\prime \prime}} .
$$

By defining $\mathrm{w}=1 / \mathrm{C}_{3}=\mathrm{P}_{\mathrm{a}}^{\prime \prime} /\left(\mathrm{P}_{\mathrm{a}}^{\prime \prime}-\mathrm{P}_{\mathrm{w}}^{\prime \prime}\right)=\mathrm{P}_{\mathrm{a}} /\left(\mathrm{P}_{\mathrm{a}}-\mathrm{P}_{\mathrm{w}}\right)$ and $\mathrm{k}=\mathrm{Q}_{1} / \mathrm{Q}_{0}$, equations (E3) and (E5) finally become

$$
\Delta \mathrm{FFR}_{\mathrm{p}}^{\prime}=\frac{\Delta \mathrm{FFR}_{\mathrm{p}}}{1-\mathrm{kw} \times \Delta \mathrm{FFR}_{\mathrm{d}}} \text { and } \Delta \mathrm{FFR}_{\mathrm{d}}^{\prime}=\frac{\Delta \mathrm{FFR}_{\mathrm{d}}}{1-\mathrm{w} \times \Delta \mathrm{FFR}_{\mathrm{p}}} .
$$

In the present study, $\mathrm{P}_{\mathrm{w}} / \mathrm{P}_{\mathrm{a}}$ was assumed to be $0.25^{6}$, and correspondingly $\mathrm{w}=1.33$. The uncertainty associated with $\mathrm{P}_{\mathrm{w}}$ was assessed by evaluating the variations in $\Delta \mathrm{FFR}_{\mathrm{p}}^{\prime}$ using the published standard deviation $\left(\mathrm{P}_{\mathrm{w}} / \mathrm{P}_{\mathrm{a}}=0.25 \pm 0.10\right)^{6}$. The estimated error in FFR prediction was $<0.02$ for $\mathrm{FFR}_{\mathrm{d}}>0.6$.

\section{VALIDATION OF THE TANDEM PREDICTION MODEL}

For tandem lesions, the distal FFR after the treatment of the distal or proximal stenosis is predicted as

$$
\mathrm{FFR}_{\mathrm{d}, \text { pred }}^{\prime}=\mathrm{FFR}_{\mathrm{p}}-\frac{\Delta \mathrm{FFR}_{\mathrm{p}}}{1-1.33 \mathrm{k} \times \Delta \mathrm{FFR}_{\mathrm{d}}} \text { or } \mathrm{FFR}_{\mathrm{p}}-\frac{\Delta \mathrm{FFR}_{\mathrm{d}}}{1-1.33 \times \Delta \mathrm{FFR}_{\mathrm{p}}},
$$

respectively ("current model"). $\mathrm{k}$ is the flow fraction of the distal main branch at the bifurcation point. To validate our mathematical models, the distal FFR measured after treating the primary target lesion $\left(\mathrm{FFR}_{\mathrm{d}}{ }_{\mathrm{d}}\right.$ ) was compared with the predicted FFR value $\left(\mathrm{FFR}_{\text {d,pred }}^{\prime}\right)$. The baseline FFR values were calculated from the initial pullback measurement. $\mathrm{k}$ was estimated with the allometric 
scaling law of flow bifurcation ${ }^{10}$ using the diameters of coronary branches obtained by quantitative coronary angiography (QCA) (Figure 2). If multiple side branches were positioned in the tandem lesion, only the largest one was considered.

To compare prediction accuracy, predicted FFR values were computed by applying the "conventional model",

$$
\text { FFR }_{d, \text { pred }}^{\prime}=\frac{\mathrm{P}_{\mathrm{d}}-\left(\mathrm{P}_{\mathrm{m}} / \mathrm{P}_{\mathrm{a}}\right) \times \mathrm{P}_{\mathrm{w}}}{\mathrm{P}_{\mathrm{a}}-\mathrm{P}_{\mathrm{m}}+\mathrm{P}_{\mathrm{d}}-\mathrm{P}_{\mathrm{w}}} \text { or } 1-\frac{\left(\mathrm{P}_{\mathrm{a}}-\mathrm{P}_{\mathrm{w}}\right) \times\left(\mathrm{P}_{\mathrm{m}}-\mathrm{P}_{\mathrm{d}}\right)}{\mathrm{P}_{\mathrm{a}} \times\left(\mathrm{P}_{\mathrm{m}}-\mathrm{P}_{\mathrm{w}}\right)} \text {, }
$$

for the treatment of proximal or distal stenosis, respectively ${ }^{5}$. The wedge pressure was estimated using the assumption of $\mathrm{P}_{w} / \mathrm{P}_{\mathrm{a}}=0.25$, as in the current model.

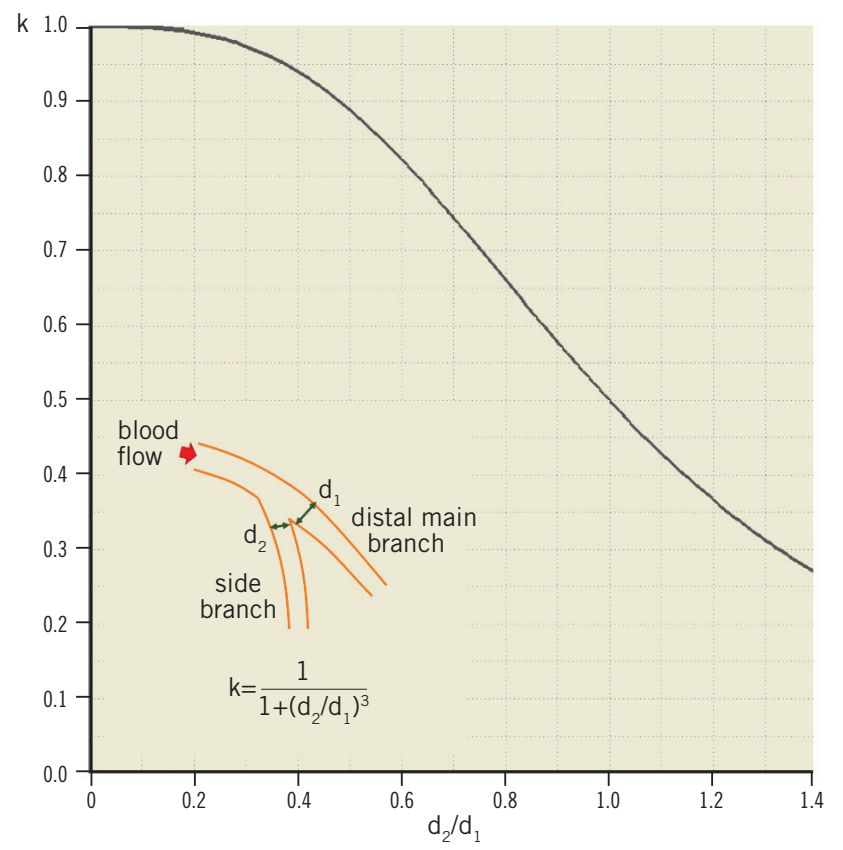

Figure 2. Plot of $k v s . d_{2} / d_{1}$. k: flow fraction of the distal main branch at the bifurcation point of interest; $d_{2} / d_{1}$ : diameter ratio of side to distal main branches at the branching point (normal segment)

\section{STUDY SUBJECTS FOR MODEL VALIDATION}

From November 2011 to May 2015, a total of 82 patients who had coronary tandem lesions with an FFR $<0.80$ at a position distal to the distal stenosis were retrospectively selected from the prospective FFR registry. A tandem lesion was defined as two separate stenoses within one epicardial coronary artery, each with a stenosis diameter $>50 \%$ by visual estimation and separated by an angiographically normal segment. After excluding patients with acute coronary syndrome, significant left main coronary artery disease, incomplete stent coverage of the target lesion, coronary spasms, in-stent restenosis, left ventricular ejection fraction $<40 \%$, regional wall motion abnormalities, or coronary artery bypass grafts, 50 tandem lesions from 50 patients with complete angiographic and serial FFR data sets were analysed.

\section{CORONARY ANGIOGRAPHIC AND FFR MEASUREMENT}

Catheterisation was performed through the femoral or radial route using standard catheters. Coronary angiograms were digitally recorded and quantitatively assessed in the Angiographic Core Laboratory (Asan Medical Center, Seoul, South Korea), using an automated edge detection system (CAAS II; Pie Medical, Maastricht, The Netherlands). QCA analysis was conducted by experienced personnel according to standard clinical definitions ${ }^{11}$.

FFR measurements were performed using 0.014 inch pressure wires (St. Jude Medical, St. Paul, MN, USA) following standard procedures $^{12}$. Under fluoroscopic guidance, the pressure wire was advanced into the coronary artery of interest to a position distal to the most distal stenosis, and steady-state maximum hyperaemia was induced by the continuous administration of $140-200 \mu \mathrm{m} / \mathrm{kg} / \mathrm{min}$ adenosine into the large antecubital vein or the central vein. During maximal hyperaemia, the pressure wire was slowly pulled back to the ostium of the coronary artery while longitudinal pressure changes were recorded. The FFR values were automatically displayed, and all pressure tracings were recorded by a RadiAnalyzer ${ }^{\mathrm{TM}}$ Xpress (St. Jude Medical) for offline analysis. Finally, the pressure wire was completely pulled back into the guiding catheter to verify that no drift had occurred during the procedure.

After FFR measurement, percutaneous coronary intervention (PCI) for functionally significant tandem lesions $\left(\mathrm{FFR}_{\mathrm{d}}<0.80\right)$ was performed. First, a drug-eluting stent was implanted at the primary target lesion with the greater $\triangle F F R$. Then, to assess the functional severity of the remaining stenosis, FFR $_{\mathrm{d}}$ was measured at the same position where $\mathrm{FFR}_{\mathrm{d}}$ was measured pre stenting. When FFR $_{\text {d }}^{\prime}$ was $<0.80$, the remaining stenosis was treated by placing another stent. All procedures, including stent sizing and optimisation, were performed with intravascular ultrasound guidance.

\section{STATISTICAL ANALYSIS}

Continuous variables are presented as mean $\pm \mathrm{SD}$, and categorical variables are presented as numbers and percentages. Linear regression analysis was performed to compare $\mathrm{FFR}_{\text {d,pred }}^{\prime}$ with $\mathrm{FFR}_{\mathrm{d}}^{\prime}$. Bland-Altman analysis was used to calculate the bias and limits of agreement between $\mathrm{FFR}_{\mathrm{d} \text {,pred }}^{\prime}-\mathrm{FFR}_{\mathrm{d}}^{\prime}$ and FFR ${ }_{\mathrm{d}}^{\prime}$. To compare the prediction models, a paired t-test and Wilcoxon signed-rank test were applied to the prediction error $\left(\mathrm{FFR}_{\mathrm{d}, \mathrm{pred}}^{\prime}-\mathrm{FFR}_{\mathrm{d}}^{\prime}\right)$ and its absolute value $\left(\left|\mathrm{FFR}_{\mathrm{d} \text {,pred }}^{\prime}-\mathrm{FFR}_{\mathrm{d}}^{\prime}\right|\right)$, respectively. Values of $\mathrm{p}<0.05$ were considered statistically significant and normality of data was tested with the Shapiro-Wilk W-test ( $\mathrm{p}>0.05)$. The Durbin-Watson statistic was calculated to test for a serial autocorrelation of the error terms in the regression models. All statistical analyses were performed using SPSS, Version 17.0 for Windows (SPSS, Inc., Chicago, IL, USA).

\section{Results \\ PATIENTS}

The baseline clinical, QCA, and FFR data in 50 patients with 50 tandem lesions are summarised in Table 1 and Table 2. The proximal stenosis was treated first in 27 (54\%) patients, while the distal 
Table 1. Baseline clinical characteristics of 50 patients.

\begin{tabular}{|c|c|c|}
\hline \multicolumn{2}{|c|}{ Variable } & Value \\
\hline \multicolumn{2}{|l|}{ Age (years) } & $63.2 \pm 9.3$ \\
\hline \multicolumn{2}{|l|}{ Men, n (\%) } & $41(82 \%)$ \\
\hline \multicolumn{2}{|c|}{ Diabetes mellitus, n (\%) } & $20(40 \%)$ \\
\hline \multicolumn{2}{|l|}{ Hypertension, n (\%) } & $33(66 \%)$ \\
\hline \multicolumn{2}{|l|}{ Smoker, n (\%) } & $8(16 \%)$ \\
\hline \multicolumn{2}{|c|}{ Hyperlipidaemia, n (\%) } & $39(78 \%)$ \\
\hline \multicolumn{2}{|c|}{ Chronic renal failure, n (\%) } & $1(2 \%)$ \\
\hline \multicolumn{2}{|c|}{ Acute coronary syndrome, n (\%) } & $8(16 \%)$ \\
\hline \multicolumn{2}{|c|}{ Left ventricular ejection fraction, \% } & $60.1 \pm 6.1$ \\
\hline \multirow{3}{*}{$\begin{array}{l}\text { Number of diseased } \\
\text { vessels, } n(\%)\end{array}$} & Single-vessel disease & $15(30 \%)$ \\
\hline & Two-vessel disease & $15(30 \%)$ \\
\hline & Three-vessel disease & $20(40 \%)$ \\
\hline \multirow{3}{*}{$\begin{array}{l}\text { Diseased coronary } \\
\text { artery, n (\%) }\end{array}$} & Left anterior descending & $37(74 \%)$ \\
\hline & Left circumflex & $1(2 \%)$ \\
\hline & Right coronary & $12(24 \%)$ \\
\hline
\end{tabular}

stenosis was treated first in the remaining $23(46 \%)$ patients. In 37 (74\%) patients, only a single stenosis was treated, with deferral of the remaining lesion.

\section{PREDICTION ACCURACY COMPARED TO A CONVENTIONAL MODEL}

The correlation between predicted and measured post-stenting FFR' values and the accuracy of the prediction models are shown in Figure 3. The current prediction model (vs. conventional) showed a closer correlation with the measured FFR $\left(\mathrm{R}^{2}=0.83\right.$ vs. 0.57$)$. Correspondingly, our current model reduced the standard deviation of prediction errors by half $(0.029 \pm 0.033$ vs. $0.027 \pm 0.068, \mathrm{p}=0.769)$ and had a greater prediction power in terms of absolute prediction errors $(0.034 \pm 0.028$ vs. $0.053 \pm 0.049$, $\mathrm{p}<0.001)$. Also, in the ischaemia prediction of the remaining lesion $\left(\mathrm{FFR}_{\mathrm{d}}^{\prime}<0.80\right)$, our current model yielded improved accuracy $(82 \%$ vs. $78 \%)$.

\section{Decision making of tandem lesion treatment DECISION DISAGREEMENT USING BASELINE $\triangle$ FFR VS. PREDICTED FFR'}

The impact of side branch flow on the post-stenting FFR gradient is shown in Figure 4A, which was analytically obtained from the current prediction model. When $\triangle F F R_{p}$ and $\triangle F F R_{d}$ appeared to be equal, the post-stenting FFR $_{\text {d,pred }}$ for the treatment of distal stenosis (vs. proximal) was higher, and the difference between post-stenting FFR' ${ }_{d, p r e d}$ increased with lower FFR $_{\mathrm{d}}$ and smaller k. Accordingly, disagreement in the decision making of the first target lesion using baseline $\triangle F F R$ and predicted post-stenting FFR $_{\text {d,pred }}^{\prime}$ was observed, as shown in Figure 4B. When $\left[\triangle F R_{d}-\right.$ $\left.\Delta \mathrm{FFR}_{\mathrm{p}}\right]$ was $>0$, the treatment of distal stenosis was predicted to be more effective in reducing ischaemia. Conversely, when $\left[\Delta \mathrm{FFR}_{\mathrm{d}}-\Delta \mathrm{FFR}_{\mathrm{p}}\right]$ was $<0$, the distal stenosis could be more severe
Table 2. QCA and FFR data in 50 tandem lesions.

\begin{tabular}{|l|l|c|}
\hline \multicolumn{2}{|c|}{ Variable } & Value \\
\hline Pre-procedural QCA data & $3.83 \pm 0.42$ \\
\hline \multirow{4}{*}{$\begin{array}{l}\text { Proximal } \\
\text { lesion }\end{array}$} & Proximal reference lumen diameter, mm & $3.23 \pm 0.42$ \\
\cline { 2 - 3 } & Distal reference lumen diameter, $\mathrm{mm}$ & $1.44 \pm 0.39$ \\
\cline { 2 - 3 } & Minimal lumen diameter, mm & $58.8 \pm 10.4$ \\
\cline { 2 - 3 } & Diameter stenosis, \% & $17.35 \pm 7.52$ \\
\cline { 2 - 3 } & Lesion length, mm & $3.14 \pm 0.42$ \\
\hline \multirow{4}{*}{$\begin{array}{l}\text { Distal } \\
\text { lesion }\end{array}$} & Proximal reference lumen diameter, mm & $2.59 \pm 0.39$ \\
\cline { 2 - 3 } & Distal reference lumen diameter, mm & $1.21 \pm 0.35$ \\
\cline { 2 - 3 } & Minimal lumen diameter, mm & $57.5 \pm 12.6$ \\
\cline { 2 - 3 } & Diameter stenosis, \% & $17.62 \pm 8.77$ \\
\cline { 2 - 3 } & Lesion length, mm & $2.01 \pm 0.48$ \\
\hline \multirow{4}{*}{$\begin{array}{l}\text { Side } \\
\text { branch }\end{array}$} & Proximal reference lumen diameter, mm & $1.87 \pm 0.43$ \\
\cline { 2 - 3 } & Distal reference lumen diameter, mm & $34.8 \pm 19 \pm 6.22$ \\
\cline { 2 - 3 } & Minimal lumen diameter, mm & $0.819 \pm 0.103$ \\
\cline { 2 - 3 } & Diameter stenosis, \% &
\end{tabular}

\section{Post-stenting QCA data}

\begin{tabular}{|l|c|}
\hline Stent number & $1.30 \pm 0.46$ \\
\hline Total stent length, mm & $30.88 \pm 13.12$ \\
\hline Minimal lumen diameter, mm & $1.69 \pm 0.48$ \\
\hline Diameter stenosis, \% & $44.0 \pm 14.8$ \\
\hline Proximal reference lumen diameter, $\mathrm{mm}$ & $3.85 \pm 0.42$ \\
\hline Distal reference lumen diameter, $\mathrm{mm}$ & $2.56 \pm 0.39$ \\
\hline
\end{tabular}

\section{FFR data}

\begin{tabular}{|l|l|}
\hline Pre-procedural FFR & $0.970 \pm 0.036$ \\
\hline Pre-procedural FFR & $0.812 \pm 0.099$ \\
\hline Pre-procedural FFR & $0.664 \pm 0.115$ \\
\hline$\triangle F F R$ of the first treated lesion & $0.158 \pm 0.103$ \\
\hline$\triangle F F R$ of the remaining lesion & $0.148 \pm 0.118$ \\
\hline Post-stenting FFR' ${ }_{d}$ across the remaining lesions & $0.816 \pm 0.080$ \\
\hline
\end{tabular}

': after treatment; FFR: fractional flow reserve; FFR,$F F R_{m}$, and $F F R_{d}$ :

FFR values at positions proximal to the tandem lesion, between stenoses and distal to the tandem lesion, respectively; k: flow fraction of the distal main branch at the bifurcation point of interest; QCA: quantitative coronary angiography

despite a larger $\triangle F F R$ across the proximal stenosis, as indicated by the "disagreement zone". The lower the $\mathrm{FFR}_{d}$ value and the higher the side branch flow, the larger the disagreement zone became.

\section{CASE EXAMPLE}

The practical application of the current prediction model is explained in Figure 5. In the case example, the FFR value at the position proximal to the tandem lesion was $\mathrm{FFR}_{\mathrm{p}}=1$, and the FFR gradients across the proximal and distal stenoses were $\Delta \mathrm{FFR}_{\mathrm{p}}=0.23$ and $\Delta \mathrm{FFR}_{\mathrm{d}}=0.08$, respectively. After the estimation of $\mathrm{k}(=0.66)$ using the diameter ratio of side to distal main 

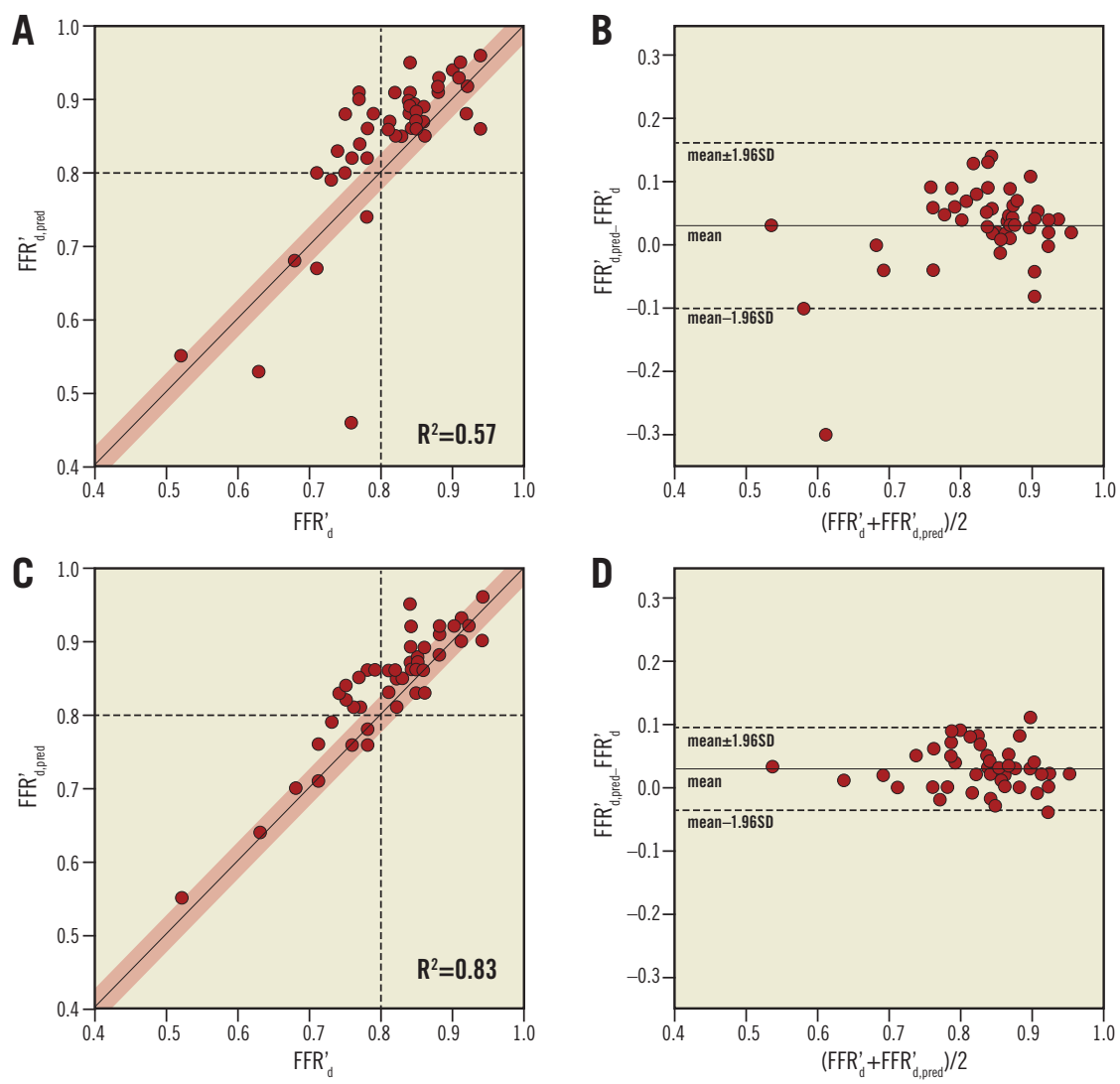

Figure 3. Plots of FFR ${ }_{d, p r e d} v s . F F R_{d}^{\prime}$ after stenosis treatment in a tandem lesion (left column) and the corresponding Bland-Altman plot (right column) for conventional $(A, B)$ and current $(C, D)$ models. For the current model, $k$ is calculated using the diameter ratio of the side to distal main branches (Figure 2). Each dot indicates a tandem lesion. The red-shaded region in the left column indicates an offset of \pm 0.03 . ': after treatment; FFR: fractional flow reserve; FFR : FFR at a position distal to the tandem lesion; pred: predicted
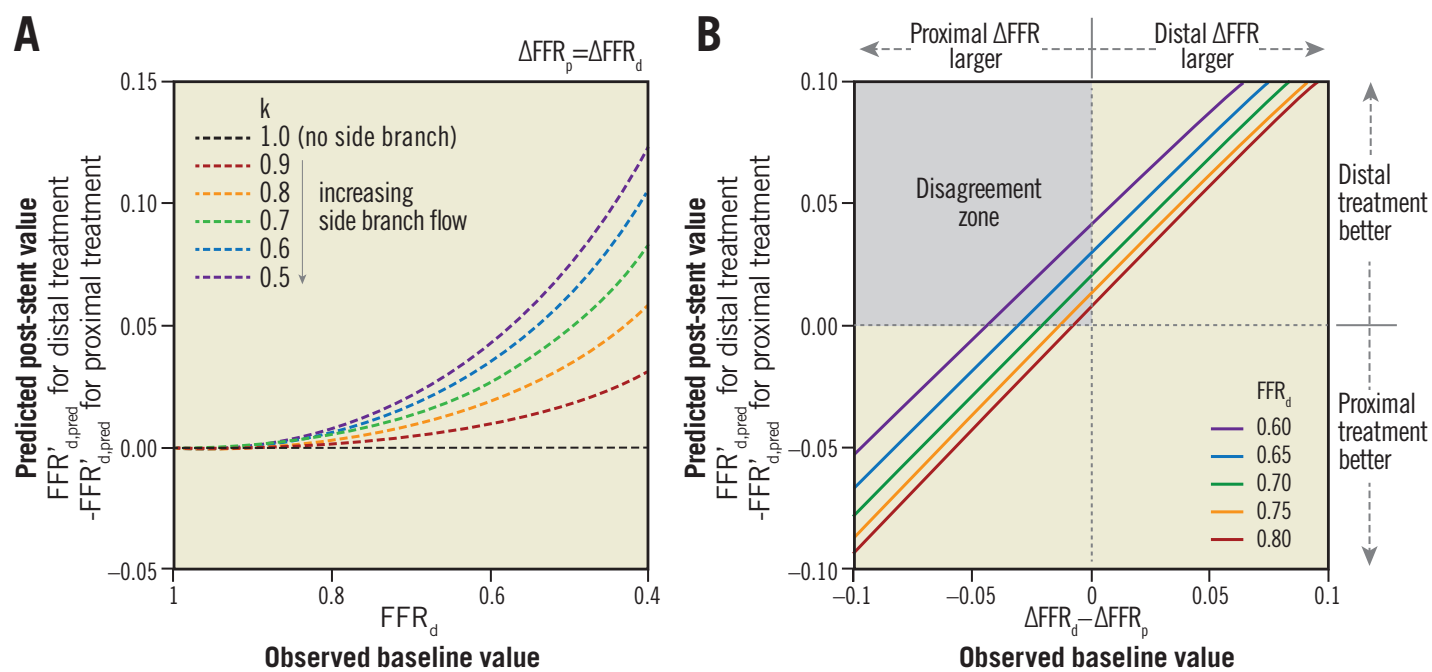

Figure 4. A disagreement in the decision making of the first target lesion using baseline $\triangle F F R$ and predicted post-stenting FFR' ${ }_{\text {dpred }}$. When the baseline $\triangle F F R_{d}$ and $\triangle F F R_{p}$ are equal, the distal stenosis (vs. proximal) is predicted to be relatively more severe (higher FFR' ${ }_{d \text {,pred }}$ for the treatment of distal stenosis) with a higher side branch flow (a smaller $k$ ) (A). When $k$ is fixed as 0.5 , the disagreement zone becomes larger with a lower baseline $F F R_{d}(B)$. ': after treatment; FFR: fractional flow reserve; $\triangle F F R$ : translesional FFR gradient; FFR : FFR at a position distal to the tandem lesion; $\triangle F F R_{p}$ and $\triangle F F R_{d}$ :FFR gradients across proximal and distal stenoses, respectively; $k$ : flow fraction of the main branch at the bifurcation point of interest; pred: predicted 


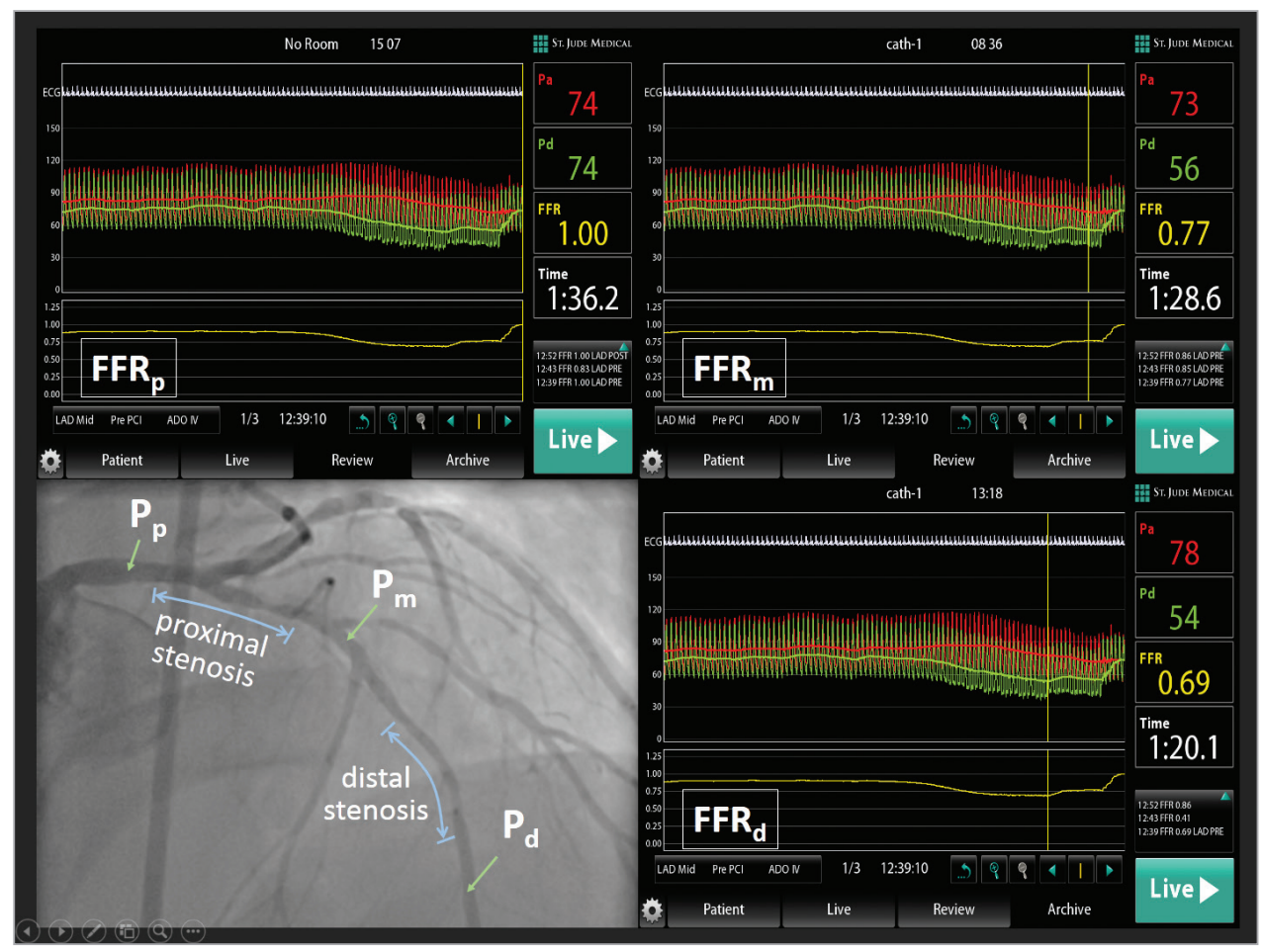

Figure 5. Case example of the use of the current prediction model to assess a tandem lesion. Using the baseline FFR gradients $(\triangle F F R=0.23$ and $\left.\triangle F F R_{d}=0.08\right)$ and the estimated $k(=0.66)$, the post-stenting $F F R_{d, p r e d}^{\prime}$ was predicted to be 0.88 or 0.75 for the treatment of proximal or distal stenosis, respectively. After treating the proximal stenosis, the measured post-stenting $F F R_{d}^{\prime}$ was 0.85 . FFR at a position proximal to the tandem lesion. FFR: fractional flow reserve; $F F R_{d}^{\prime}$ : FFR distal to the tandem lesion after treatment; $\triangle F F R_{p}$ and $\triangle F F R_{d}$ : FFR gradients across proximal and distal stenoses, respectively; $k$ : flow fraction of the distal main branch at the bifurcation point of interest; pred: predicted; QCA: quantitative coronary angiography

branches $\left(\mathrm{d}_{2} / \mathrm{d}_{1}=0.80\right)$, the $F F R_{\mathrm{d}, \text { pred }}^{\prime}$ was predicted to be 0.88 or 0.75 for the treatment of proximal or distal stenosis, respectively. The predicted FFR' ${ }_{\text {d,pred }}$ indicated that the treatment of proximal stenosis was more effective and the treatment of distal stenosis was not necessary. For this patient, only the proximal stenosis was treated, and the measured post-stenting FFR ${ }_{d}^{\prime}$ was 0.85 .

\section{UTILISATION OF A $\triangle$ FFR MAP}

To facilitate clinical decision making, optimal treatment strategies for tandem lesions were suggested by the $\Delta F F R$ map based on the current prediction model in which the baseline distal FFR was functionally significant $\left(\mathrm{FFR}_{d}<0.80\right)$ (Figure 6). The $\triangle$ FFR map was divided into three sub-regions by a red line (the same FFR' ${ }_{\text {d,pred }}$ for the treatment of proximal and distal stenoses), blue line (FFR' ${ }_{\text {d,pred }}=0.8$ for the treatment of distal stenosis) and green line $\left(\mathrm{FFR}_{\mathrm{d}, \mathrm{pred}}^{\prime}=0.8\right.$ for the treatment of proximal stenosis). Accordingly, tandem lesions were categorised into "treat only distal", "treat only proximal" and "treat both". Depending on the side branch flow, the boundaries of "treat only distal" (red and blue lines) were modified, while the green line remained constant. Therefore, evaluation and comparison of $\mathrm{FFR}_{\mathrm{d} \text {,pred }}$ using the current prediction model were required in the blue area to determine whether only the distal lesion or both lesions should be treated, as well as in the orange area to decide whether the

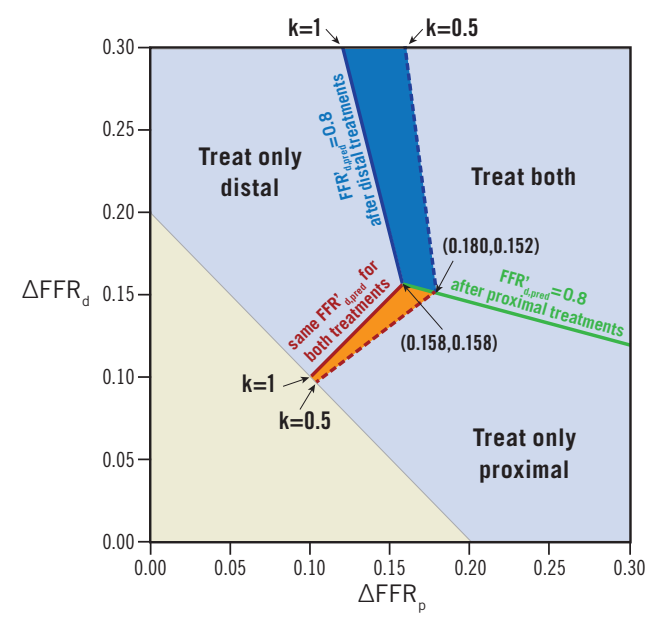

Figure 6. $\triangle F F R$ map for clinical decision making in tandem lesions. The evaluation and comparison of post-stenting FFR ${ }_{d, \text { pred }}$ using the current prediction model are required in the blue and orange areas, where the boundaries are dependent on $k$; otherwise, the decision can be directly made. Here, $F F R_{p}=1$ is assumed, and, for the patients with $F F R_{p}=1$, the prediction accuracy of this map was 91\% (20/22). ': after treatment; FFR: fractional flow reserve; $\triangle F F R$ : translesional FFR gradient; $\triangle F F R_{p}$ and $\triangle F F R_{d}: F F R$ gradients across proximal and distal stenoses, respectively; $k$ : flow fraction of the distal main branch at the bifurcation point of interest 
distal or proximal lesion should be treated. For the patient shown in Figure 5, the baseline FFR gradients $\left(\triangle \mathrm{FFR}_{\mathrm{p}}=0.23\right.$ and $\Delta \mathrm{FFR}_{\mathrm{d}}=0.09$ ) indicated that only the proximal lesion should be treated.

\section{Discussion}

While FFR is reliable for assessing the haemodynamic significance of coronary artery stenosis, the functional severity of individual stenoses cannot be assessed without repeated FFR measurements in tandem lesions with an interposed side branch. Therefore, the aim of our present study was to provide and validate a mathematical prediction model for post-stenting FFR $_{\text {d,pred }}^{\prime}$. The major findings of our present study were: 1) a mathematical prediction model reflecting the actual severity of individual stenoses and the effect of interposed side branches allowed us to predict post-stenting FFR' accurately across the remaining stenosis $\left(\mathrm{R}^{2}=0.83\right.$ between predicted vs. measured FFR'); and 2) this prediction model was helpful in deciding which stenosis was more severe and whether the remaining lesion after the first treatment was functionally significant.

Our current results showed an improvement in accuracy using the current prediction model. This may be explained by three factors. First, the effect of interposed side branches was considered in the current model. Although the conventional model achieved high prediction accuracy for tandem lesions with negligible side branches ${ }^{6}$, larger discrepancies were observed in the population with various sizes of side branch. Second, the conventional prediction model overestimated the $\Delta F_{F R}$ by ignoring the pressure drop from the coronary ostium to the tandem lesion $\left(\mathrm{FFR}_{\mathrm{p}} \neq 1\right)$. In 27 tandem lesions, including 22 left anterior descending arteries, consideration of FFR $(0.947 \pm 0.032)$ improved the accuracy of our prediction model, although further evaluation of dynamic changes in FFR' ${ }_{p}^{\prime}$ post stenting is needed to clarify this issue ${ }^{7}$. Third, the FFR-based (not pressure-based) calculation in our prediction model was amenable to variations in aortic pressure during the pullback measurement, independently of blood pressure ${ }^{13}$.

The measurement of wedge pressure $\left(\mathrm{P}_{\mathrm{w}}\right)$ is considered a main obstacle to the clinical use of prediction models $\mathrm{s}^{6,12}$, and, in tandem lesions, direct measurements for both side and distal main branches are virtually impossible. In our current model, the need for wedge pressure information was eliminated with the assumption of $\mathrm{P}_{w} / \mathrm{P}_{\mathrm{a}}=0.25$. The prediction error of using the fixed $\mathrm{P}_{w} / \mathrm{P}_{a}$ was demonstrated to be within the clinically acceptable range $\left(<0.02\right.$ when $\left.\mathrm{FFR}_{\mathrm{d}}>0.6\right)$. The flow bifurcation ratio $(\mathrm{k})$ was also estimated without direct measurements. The plot of $\mathrm{k}$ vs. $\mathrm{d}_{2} / \mathrm{d}_{1}$ shown in Figure 2 can be simply used for the estimation of $\mathrm{k}$, and, for tandem lesions with no side branch, post-stenting FFR prediction can be achieved by applying $\mathrm{k}=1$. Considering the prediction error associated with $\mathrm{k}$ estimation $(\leq 0.01$ per 0.1 of $\mathrm{k}$ when $\mathrm{FFR}_{\mathrm{d}}>0.6$ in Figure 4A), the $\mathrm{k}$ value obtained with a rough estimation of the diameter ratio did not hamper the prediction accuracy, and therefore the real-time application of the current model would be feasible in a clinical context. Moreover, the $\triangle \mathrm{FFR}$ map that was provided based on the current prediction model facilitates immediate decision making for the optimal treatment strategy for tandem lesions. Consequently, the current model is more customised to the clinical context, allowing us to predict post-stenting FFR' accurately without wedge pressure measurements.

A recent study reported that the FFR gradient $(\triangle F F R)$ was theoretically the same as the pressure gradient across a stenosis, but was a more feasible and practical index for comparing the relative functional severity between two separate lesions ${ }^{3}$. Thus, it has been recommended that the stenosis with the larger $\triangle F F R$ should be treated first, and that the post-stenting FFR $_{d}^{\prime}$ across the remaining stenosis should then be evaluated. However, our prediction model showed that there was a disagreement zone in which the decision making for more effective treatment was different between the evaluation of the baseline $\triangle F F R$ and the predicted post-stenting FFR ${ }_{\text {d,pred }}$. With the flow-dependent property of pressure gradients, proximal and distal stenoses mutually affect each $\triangle F F R$. If there is no side branch between two separate lesions, the baseline $\Delta F F R$ values equally underestimate the true severities of both stenoses, and thus reveal which stenosis is more severe. However, because an increase in side branch flow attenuates the recovery of the coronary flow across the proximal stenosis after the treatment of the distal stenosis and not vice versa, equal baseline $\Delta F F R$ values imply that the distal stenosis is more severe. In the same context, the interpretation of our current model is consistent with the recent reports that stenting a downstream stenosis produced little change in the FFR gradient across the intermediate left main disease $\mathrm{e}^{14,15}$, because the treatment of a stenosis in the left anterior descending or left circumflex restores a fraction of the flow rate running through the left main. Nonetheless, for the FFR prediction of tandem lesions with left main diseases, further investigations should be made. These findings suggest that treatment of the proximal stenosis with a larger $\triangle F F R$ could be less effective, particularly with more severe lesions and higher side branch flow.

Furthermore, our current prediction model, unlike the simple comparison of baseline $\triangle F F R$ values, makes it possible to simulate the residual FFR after the first treatment and thus to plan for a tailored stent before the procedure. For instance, there may be technical difficulties in delivering the second stent to the distal site through the primarily stented proximal segment. If the presence of residual ischaemia is predicted and both stenoses should be treated, operators can avoid unnecessarily complex procedures by first treating the distal lesion.

\section{Limitations}

Our current study had some potential limitations. First, the small sample size and potential selection bias may have affected the results. Second, the linear relationship between the cycleaveraged pressure and flow rate could ignore the transient 
characteristics of coronary flows, and did not include the quadratic term associated with flow separation and turbulence around the stenosis, which may have caused an additional pressure drop $^{16,17}$. Third, the wedge pressures for the distal main and side branches were assumed to be equal. Fourth, our current model did not include the assessment of left main lesions with downstream stenoses and cannot be applied to lesions with more than two stenoses, multiple large side branches, or diffuse lesions. Fifth, the outcome of FFR prediction could be impaired when distal embolisation occurs as a consequence of extensive vessel manipulation or degree of platelet inhibition. Sixth, the bifurcation angle was not considered in the calculation, which could be an important determinant for the flow fraction to branches ${ }^{18}$. Finally, despite our efforts to apply the prediction model simply in daily practice, its clinical relevancy needs to be further validated with subsequent clinical studies.

\section{Conclusion}

Post-stenting FFR in tandem lesions with an interposed side branch can be accurately predicted without the measurement of wedge pressure. By predicting which stenosis is more severe and/or whether the remaining lesion after the first treatment is functionally significant, this tandem prediction model can help in planning optimised stent implantation and facilitate the stent procedure.

\section{Impact on daily practice}

Post-stenting FFR in tandem lesions with an interposed side branch can be accurately predicted without the measurement of wedge pressure. By predicting which stenosis is more severe and/or whether the remaining lesion after the first treatment is functionally significant, a tandem prediction model can help to plan optimised stent implantation.

\section{Funding}

This study was supported by a grant from the Korea Healthcare Technology R\&D Project, Ministry for Health \& Welfare Affairs, Republic of Korea (HI14C0517 and HI12C0630), a National Research Foundation of Korea (NRF) grant funded by the Korean government (MSIP) (NRF-2015R1A2A2A04003034), and by the Basic Science Research Program through the National Research Foundation of Korea (NRF), funded by the Ministry of Science, ICT \& Future Planning (NRF-2013R1A1A1058711).

\section{Conflict of interest statement}

The authors have no conflicts of interest to declare.

\section{References}

1. Pijls NH, de Bruyne B, Peels K, van der Voort PH, Bonnier HJ, Bartunek J, Koolen JJ. Measurement of fractional flow reserve to assess the functional severity of coronary-artery stenoses. $N$ Engl J Med. 1996;334:1703-8.
2. Pijls NH. Fractional flow reserve to guide coronary revascularization. Circ J. 2013;77:561-9.

3. Park SJ, Ahn JM, Pijls NH, De Bruyne B, Shim EB, Kim YT, Kang SJ, Song H, Lee JY, Kim WJ, Park DW, Lee SW, Kim YH, Lee CW, Park SW. Validation of functional state of coronary tandem lesions using computational flow dynamics. Am J Cardiol. 2012;110:1578-84.

4. Kim HL, Koo BK, Nam CW, Doh JH, Kim JH, Yang HM, Park KW, Lee HY, Kang HJ, Cho YS, Youn TJ, Kim SH, Chae IH, Choi DJ, Kim HS, Oh BH, Park YB. Clinical and physiological outcomes of fractional flow reserve-guided percutaneous coronary intervention in patients with serial stenoses within one coronary artery. JACC Cardiovasc Interv. 2012;5:1013-8.

5. De Bruyne B, Pijls NH, Heyndrickx GR, Hodeige D, Kirkeeide R, Gould KL. Pressure-derived fractional flow reserve to assess serial epicardial stenoses theoretical basis and animal validation. Circulation. 2000;101:1840-7.

6. Pijls NH, De Bruyne B, Bech GJ, Liistro F, Heyndrickx GR, Bonnier HJ, Koolen JJ. Coronary pressure measurement to assess the hemodynamic significance of serial stenoses within one coronary artery: validation in humans. Circulation. 2000;102:2371-7.

7. Saito N, Matsuo H, Kawase Y, Watanabe S, Bao B, Yamamoto E, Watanabe H, Nakatsuma K, Ueno K, Kimura T. In vitro assessment of mathematically-derived fractional flow reserve in coronary lesions with more than two sequential stenoses. J Invasive Cardiol. 2013;25:642-9.

8. Li Y, Gutiérrez-Chico JL, Holm NR, Yang W, Hebsgaard L, Christiansen EH, Mæng M, Lassen JF, Yan F, Reiber JH, Tu S. Impact of Side Branch Modeling on Computation of Endothelial Shear Stress in Coronary Artery Disease: Coronary Tree Reconstruction by Fusion of 3D Angiography and OCT. J Am Coll Cardiol. 2015;66:125-35.

9. Pijls N, Van Son J, Kirkeeide R, De Bruyne B, Gould K. Experimental basis of determining maximum coronary, myocardial, and collateral blood flow by pressure measurements for assessing functional stenosis severity before and after percutaneous transluminal coronary angioplasty. Circulation. 1993;87: 1354-67.

10. Murray CD. The physiological principle of minimum work applied to the angle of branching of arteries. J Gen Physiol. 1926;9: 835-41.

11. Popma JJ, Leon MB, Moses JW, Holmes DR, Cox N, Fitzpatrick M, Douglas J, Lambert C, Mooney M, Yakubov S, Kuntz RE; SIRIUS Investigators. Quantitative assessment of angiographic restenosis after sirolimus-eluting stent implantation in native coronary arteries. Circulation. 2004;110:3773-80.

12. Kern MJ, Lerman A, Bech JW, De Bruyne B, Eeckhout E, Fearon WF, Higano ST, Lim MJ, Meuwissen M, Piek JJ, Pijls NH, Siebes M, Spaan JA; American Heart Association Committee on Diagnostic and Interventional Cardiac Catheterization, Council on Clinical Cardiology. Physiological assessment of coronary artery disease in the cardiac catheterization laboratory: a scientific statement from the American Heart Association Committee on 
Diagnostic and Interventional Cardiac Catheterization, Council on Clinical Cardiology. Circulation. 2006;114:1321-41.

13. Pijls NH, Van Gelder B, Van der Voort P, Peels K, Bracke FA, Bonnier HJ, El Gamal MI. Fractional flow reserve. A useful index to evaluate the influence of an epicardial coronary stenosis on myocardial blood flow. Circulation. 1995;92:3183-93.

14. Daniels DV, van't Veer M, Pijls NH, van der Horst A, Yong AS, De Bruyne B, Fearon WF. The impact of downstream coronary stenoses on fractional flow reserve assessment of intermediate left main disease. JACC Cardiovasc Interv. 2012;5: 1021-5.

15. Fearon WF, Yong AS, Lenders G, Toth GG, Dao C, Daniels DV, Pijls NH, De Bruyne B. The impact of downstream coronary stenosis on fractional flow reserve assessment of intermediate left main coronary artery disease: human validation. JACC Cardiovasc Interv. 2015;8:398-403.

16. Gould KL. Pressure-flow characteristics of coronary stenoses in unsedated dogs at rest and during coronary vasodilation. Circ Res. 1978;43:242-53.

17. Siebes M, Verhoeff BJ, Meuwissen M, de Winter RJ, Spaan JA, Piek JJ. Single-wire pressure and flow velocity measurement to quantify coronary stenosis hemodynamics and effects of percutaneous interventions. Circulation. 2004;109:756-62.

18. Huo Y, Finet G, Lefevre T, Louvard Y, Moussa I, Kassab GS. Which diameter and angle rule provides optimal flow patterns in a coronary bifurcation? J Biomech. 2012;45:1273-9. 